\title{
Drag-Reduction Performance Evaluation of Controllable Hybrid Steering Drilling System
}

\author{
Jianyan Zou $\mathbb{D}^{1}{ }^{1}$ Ping Chen, ${ }^{1}$ Tianshou Ma, ${ }^{1}$ Yang Liu, ${ }^{2}$ and Xingming Wang ${ }^{3}$ \\ ${ }^{1}$ State Key Laboratory of Oil and Gas Reservoir Geology and Exploitation, Southwest Petroleum University, Chengdu 610500, \\ China \\ ${ }^{2}$ School of Mechatronic Engineering, Southwest Petroleum University, Chengdu 610500, China \\ ${ }^{3}$ State Key Laboratory of Oil and Gas Reservoir Geology and Exploitation, Chengdu University of Technology, Chengdu 610059, \\ China
}

Correspondence should be addressed to Jianyan Zou; 201711000078@stu.swpu.edu.cn

Received 28 November 2020; Revised 15 January 2021; Accepted 3 March 2021; Published 20 March 2021

Academic Editor: Qilong Xue

Copyright (c) 2021 Jianyan Zou et al. This is an open access article distributed under the Creative Commons Attribution License, which permits unrestricted use, distribution, and reproduction in any medium, provided the original work is properly cited.

The excessive drag/torque and the backing pressure is an important factor that restricts the improvement of the penetration rate and the extension of the drilling in the sliding drilling process of extended-reach wells and horizontal wells. To deal with this problem, this paper developed a novel controllable hybrid steering drilling system (CHSDS) based on the friction-reducing principle of a rotating drill string. The CHSDS is composed of a gear clutch, hydraulic system, and measurement and control system. By controlling the meshing and separation of the clutch with the mud pulse signal, the CHSDS has two working states, which leads to two boundary conditions. Combined with the stiff-string drag torque model, the effects of the drilling parameters on the friction-reducing performance of the CHSDS are analyzed systematically. The results show that the friction reduction effect in the inclined section is the most significant, followed by that in the horizontal section, whereas there is almost no impact in the vertical section. Friction reduction increases with the rotary speed and the drilling fluid density, whereas it decreases with the increase in the surface weight-on-bit and the bit reaction torque. Field tests confirm the separation and meshing function of the CHSDS. The developed controllable hybrid steering and friction-reducing technology provides an alternative approach for the safe and high-efficiency drilling of horizontal wells.

\section{Introduction}

Realizing economical and high-efficiency exploitation of unconventional oil and gas resources depends on combining horizontal drilling and hydraulic fracturing technologies [1]. However, owing to the limitations of the rig equipment and the performance of horizontal well drilling tools, the issues of low drilling efficiency and long well construction period are common in unconventional horizontal wells in China [2]. Considering shale gas horizontal well drilling as an example, at a particular vertical depth and a domestic horizontal section that is shorter than that of North America, the domestic drilling cycle is 3.6-4 times than that in North America $[3,4]$. This is primarily because the ultrahigh drag and torque between the drill string and the wellbore wall and the induced severe backing pressure effect have become some of the main technical bottlenecks restricting the optimal and rapid drilling of horizontal wells in unconventional resources.

To solve the above-mentioned drilling problems, scholars have started from the fundamental principles of tribology, including lowering the friction coefficient, reducing the normal contact force, and altering the frictional force direction, to conduct research on drag-reducing technologies in horizontal drilling $[5,6]$. Thus, various advanced drag-reduction tools are developed and successful field applications are achieved, such as drill pipe bearing subs, hydraulic oscillators, rotary steering systems (RSSs), and drill string rocking systems [7-10]. However, all the above methods have different degrees of limitation $[11,12]$. 
A drill pipe bearing sub is affected by the wellbore quality and the installation number, resulting in a poor drag-reduction effect [13-15]. For instance, a hydraulic oscillator is limited by the high circulating pressure loss and the short service life. Moreover, a high-frequency vibration can easily damage downhole measuring instruments [16-18]. An RSS has significant and potential risks of sticking and burying associated with its own structural defects, and its service cost is comparatively high [19-21]. Large-scale applications and promotions are yet to be realized for a drill string rocking system because the friction-reducing mechanism and the automatic control technology are not thoroughly understood [22-24]. Therefore, a complete understanding of the defects of the existing mechanical drag-reduction technology is developed, and an in-depth study on the mechanism of friction reduction in horizontal wells is conducted. Finally, based on the principle of friction reduction by a rotary drill string, a novel controllable hybrid steering drilling system (CHSDS) is developed, which can switch freely between meshing and separation states by receiving remotely controlled commands from the ground.

In the evaluation of the effect of drag-reduction systems, it is necessary to determine the corresponding boundary conditions and build a mechanical model according to the actual working state of the drilling system being examined [25]. Because there are two working states of meshing and separation in the actual drilling of the CHSDS, the boundary conditions of the traditional drag torque model are no longer applicable. Therefore, the existing friction torque prediction model cannot be directly used to evaluate the drag-reduction effect of the CHSDS.

Therefore, based on the actual working conditions of the CHSDS, the boundary conditions of its separation or meshing states and of the bit are determined. The dragreduction performance of the CHSDS is analyzed by combining with the classical drag torque model of the drill string. The field test verifies the remote separation and meshing functions of the CHSDS, providing the basis for the drag-reduction performance test and the subsequent application of the CHSDS.

\section{Operating Principle and Structure of CHSDS}

2.1. Operating Principle of CHSDS. During the sliding drilling process of the conventional sliding steering drilling system, the bottom hole assembly (BHA) is as shown in Figure 1(a). It comprises a bit, bent sub, positive displacement motor (PDM), and measurement while drilling (MWD). The drill string does not rotate but slides along the axis of the borehole wall. The deviation and azimuth angles of the wellbore are changed by the sliding of the steering tool face, thereby controlling the wellbore trajectory. When the actual wellbore trajectory deviates from the designed one and needs to be adjusted, the rotary table is manually controlled to rotate it an angle to rotate the tool face of the drill tool assembly to the specified direction.

An RSS can be classified into push-the-bit and point-thebit, according to the steering mode. When the push-the-bit system operates, it controls three wing ribs to push against the well wall according to the actual well deviation, azimuth data, and predetermined well trajectory; this ensures the bit points to the direction to be drilled. The point-the-bit system depends on the biasing mechanism inside the RSS to bias the mandrel; therefore, there is an angle between the axes of the rotating drill string and borehole. Finally, rotary steering is realized by the rotation angle of the drill bit. As shown in Figure 1(b), the RSS rotates while drilling, which transforms the axial friction of the drill string into circumferential friction torque, thus reducing the friction resistance of the drill string.

As can be seen from Figure 1(c), the steering method of the CHSDS is the same as the conventional sliding steering drilling method. The inclination and azimuth angles of the well are controlled by a rotating turntable in the meshing state. In the drag-reduction drilling mode, when the system is in the separation state, the upper drill string rotates to convert the axial friction part of the drill string into the circumferential friction torque. This significantly reduces the drill string friction, which is similar to rotary steering drilling. The lower drill string slide drills with the stable tool face. Therefore, the CHSDS includes three working modes:

(1) Conventional sliding steering drilling mode (meshing)

(2) Conventional rotating drilling mode (meshing)

(3) Controllable hybrid steering friction-reducing mode (separation)

2.2. Structural Design of CHSDS. The CHSDS is mainly composed of a measurement and control system, hydraulic system, and clutch unit. The structure is shown in Figure 2.

The functions of the measurement and control system are to detect the mud pressure pulse, identify the ground command, start the motor and solenoid valve drive circuit, and move the piston in a predetermined direction of the ground. Moreover, the system should realize effective separation or engagement of the tool clutch device and effectively control the working mode of the drag-reduction tool on the ground.

As shown in Figure 2(a), the measurement and control system mainly includes pressure pulse detection, signal filtering and amplification, A/D conversion, a microcontroller, and a motor solenoid valve drive circuit.

The main roles of the hydraulic system are to execute the instruction of the downhole microcontroller, inject hydraulic oil into a specified oil cylinder, and drive the piston to move in the predetermined direction. It can be seen from Figure 2(b) that it is mainly composed of a hydraulic cylinder, motor and pump, pressure relief valve, 3/2 solenoid valve, check valve, and double-acting oil cylinder.

The main objective of the clutch unit is to separate or transfer the torque from the upper drill string to the lower drill string. As shown in Figure 2(c), it mainly includes an internal gear, an outer gear, a piston shaft, a clutch outer cylinder, and a bearing bush. The hydraulic system drives the piston shaft to move back and forth to drive the separation and meshing of the internal and outer gears to 


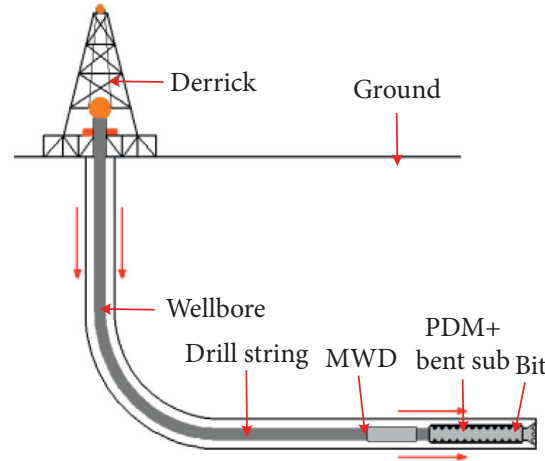

(a)

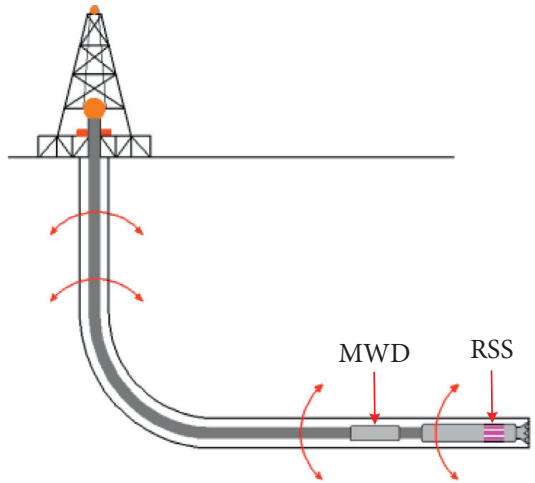

(b)

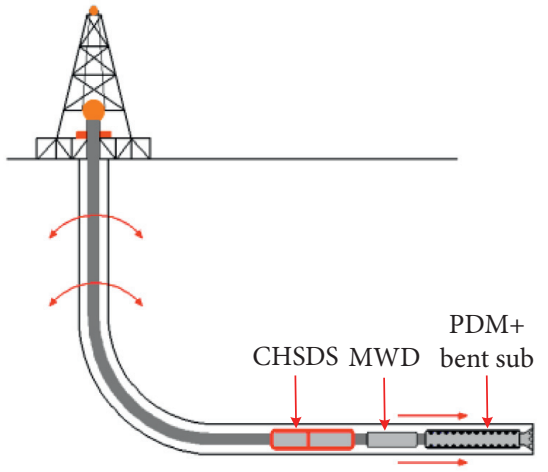

(c)

Figure 1: Comparison of CHSDS and conventional horizontal well drilling method.

realize the separation and meshing functions of the CHSDS.

The principle prototype of the CHSDS is depicted in Figure 3.

2.3. Functional Testing of CHSDS. The CHSDS function test is conducted to test whether it can realize the control command on the ground and complete the separation or meshing function in the downhole.

2.3.1. Basic Parameters of Test Well. The depth of the test well is $746 \mathrm{~m}$, the depth of the deviation point is $545 \mathrm{~m}$, the maximum deviation angle is $22.15^{\circ}$, the length of the openhole section is $201 \mathrm{~m}$, and the drilling fluid density is $1080 \mathrm{~kg} / \mathrm{m}^{3}$. The BHA comprises a $\Phi 215.9 \mathrm{~mm}$ bit, joint, $\Phi 172 \mathrm{~mm}$ drill collar, $\Phi 172 \mathrm{~mm}$ CHSDS, switching joint, and $\Phi 127 \mathrm{~mm}$ drill pipe.

2.3.2. Process and Results of CHSDS Function Test. Figure 4 displays the CHSDS tripping in and out. The process of the CHSDS function test is as follows:

(a) The CHSDS is in the meshing state, connected to the BHA, and is subsequently implemented in the bottom hole.

(b) The pump strokes number per minute is kept at 40 , and the rotary speed is $30 \mathrm{rpm}$. The drilling tool is lifted $9 \mathrm{~m}$, and the hanging weight and the strokes number per minute are recorded.

(c) The pump strokes number per minute is kept at 40. The drilling stem is raised and lowered at a constant speed, and the hanging weight is recorded.

(d) The separation command is launched, and subsequently step (b) is repeated.

(e) The meshing command is launched. The CHSDS is tripped out and disassembled to examine the data stored by the downhole microcontroller.

The test results are as follows.
The data in Table 1 show that the system can effectively execute the separation command sent from the ground. After tripping out, it is found that the CHSDS cannot be rotated with a chain clamp. This suggests that it is in a state of meshing. The disassembly of the CHSDS extracts the pulse signal data stored in the microcontroller. It is found that the CHSDS receives the command sent from the ground completely and accurately. The above results indicate that the CHSDS can accurately accept and identify ground mud pulse signals and effectively implement the meshing and separation commands.

\section{Drag-Reduction Performance Modeling}

The CHSDS is developed according to the principle of rotary drill string drag reduction, and, subsequently, its function test is completed. To better guide the field applications of the CHSDS, it is necessary to predict and evaluate the dragreduction performance. Therefore, the mathematical model for the CHSDS analysis is described below.

3.1. Basic Assumptions. In the analysis of the drill string friction based on Coulomb's theorem, the solution of the normal contact force is the key. The contact state between the drill string and the borehole wall is uncertain because of factors; therefore, it is very difficult to accurately solve the normal contact force. Thus, it is necessary to make appropriate assumptions about the contact and deformation of the drill string [26-28]:

(1) The drill string is in continuous contact with the borehole wall, the borehole wall is rigid, and the deformation of the drill string is within the elastic range

(2) The centerline of the drill string coincides with the wellbore track

(3) The gravity, normal force, mud buoyancy, and friction force of the drill string unit are evenly distributed on the drill string element

(4) The drill string element is an arc with a constant curvature in the spatial slanting plane 
(5) The dynamic load of the drill string is not considered

3.2. Governing Equations. It is necessary to consider the effects of the borehole bending and drill string stiffness on the tension and torque, as well as the drilling fluid damping and the axial and circumferential components of the friction during rotary drilling. Therefore, a mathematical model $[29,30]$ is used to calculate the friction and the torque of the drill string during drilling with the CHSDS.

$$
\left\{\begin{array}{l}
\frac{\mathrm{d} M_{t}}{\mathrm{~d} s}=f_{1} R_{o} N+m_{0}, \\
\frac{\mathrm{d} T_{t}}{\mathrm{~d} s}+k_{b} E I \frac{\mathrm{d} k_{b}}{\mathrm{~d} s}-f_{2} N-C v-B+q_{m} \vec{e}_{g} \cdot \vec{e}_{t}=0, \\
-\frac{\mathrm{d}^{2} M_{b}}{\mathrm{~d} s^{2}}+T_{t} k_{b}+k_{n}\left(k_{b} M_{t}+k_{n} M_{b}\right)+N_{n}+f_{1} N_{b}+q_{m} \vec{e}_{g} \cdot \vec{e}_{n}=0, \\
-\frac{\mathrm{d}\left(k_{b} M_{t}+k_{n} M_{b}\right)}{\mathrm{d} s}-k_{n} \frac{\mathrm{d} M_{b}}{\mathrm{~d} s}+N_{b}-f_{1} N_{n}+q_{m} \vec{e}_{g} \cdot \vec{e}_{b}=0,
\end{array}\right.
$$

where

$$
\left\{\begin{array}{l}
f_{1}=\frac{\omega R_{o} f}{\sqrt{v^{2}+\left(\omega R_{o}\right)^{2}}}, \\
f_{2}=\frac{v f}{\sqrt{v^{2}+\left(\omega R_{o}\right)^{2}}}, \\
N=\sqrt{N_{n}^{2}+N_{b}^{2}}, \\
C=\frac{2 \pi \mu}{\ln / D_{w}^{2 R_{o}}}, \\
m_{o}=2 \pi \omega R_{o}^{3}\left[\frac{\sqrt{v^{2}+\left(\omega R_{o}\right)^{2}}}{D_{w}-2 R_{o}}\right] \\
B=\frac{2 \pi R_{o} \tau v}{\sqrt{v^{2}+\left(\omega R_{o}\right)^{2}}},
\end{array}\right.
$$

where $M_{t}$ is the drill string torque; $M_{b}$ is the drill string bending moment, $N \cdot m ; T_{t}$ is the axial tension of the drill string, $N ; k_{b}$ is the borehole curvature; $k_{n}$ is the natural tortuosity of the centerline of the borehole, $\mathrm{rad} / \mathrm{m} ; E$ is the elastic modulus, $\mathrm{GPa}$; $I$ is the moment of inertia of the drill string, $m^{4} ; D_{w}$ is the borehole diameter; $R_{o}$ is the outside radius of the drill string, $m$; $\omega$ is the rotary angular velocity of the drill string, $\mathrm{rad} / \mathrm{s} ; v$ is the axial velocity of the drill string, $\mathrm{m} / \mathrm{s} ; q_{m}$ is the weight per unit length of the drill string, $\mathrm{kN} / \mathrm{m}$; $\tau$ is the shear stress of the drilling fluid, $\mathrm{Pa}$; and $\mu$ is the dynamic viscosity of the drilling fluid, $\mathrm{N} \cdot \mathrm{s} / \mathrm{m}^{2}$.
Because $k_{n}$ and $k_{b}$ are small and their product is minimal, the term containing the product of $k_{n}$ and $k_{b}$ can be ignored [31]. Moreover, when the minimum curvature method is used, the measurement point adjacent to the borehole axis is a circular arc on a spatial inclined plane, and the borehole torsion is always in the close plane. Furthermore, $k_{n}=0$ can be seen from the definition of the close section plane [5].

$$
\left\{\begin{array}{l}
\vec{e}_{g} \cdot \vec{e}_{t}=\cos \alpha, \\
\vec{e}_{g} \cdot \vec{e}_{n}=\frac{k_{\alpha}}{k_{b}} \sin \alpha, \\
\vec{e}_{g} \cdot \vec{e}_{b}=-\frac{k_{\varphi}}{k_{b}}(\sin \alpha)^{2}, \\
\vec{e}_{g}=-\cos \alpha \vec{e}_{t}+\frac{k_{\alpha}}{k_{b}} \sin \alpha \vec{e}_{n}+\frac{k_{\varphi}}{k_{b}}(\sin \alpha)^{2} \vec{e}_{b},
\end{array}\right.
$$

where $\vec{e}_{t}, \vec{e}_{n}$, and $\vec{e}_{b}$ are the unit basis vectors of the natural coordinate system, dimensionless; $\vec{e}_{g}$ is the drill string gravity basis vector, dimensionless; $k_{\alpha}$ is the deviation $\mathrm{rate}, \mathrm{rad} / \mathrm{m} ; k_{\varphi}$ is the azimuth rate of change, $\mathrm{rad} / \mathrm{m} ; \alpha$ is the inclination angle, $\mathrm{rad} ; k_{f}$ is the linear floating weight coefficient of the drill string, dimensionless.

Simultaneously, the Frenet-Serret [32] equation (3) is substituted into equation (1), and the following equation is obtained:

$$
\left\{\begin{array}{l}
\frac{\mathrm{d} M_{t}}{\mathrm{~d} s}=f_{1} R_{o} N+m_{0} \\
\frac{\mathrm{d} T_{t}}{\mathrm{~d} s}+k_{b} E I \frac{\mathrm{d} k_{b}}{\mathrm{~d} s}-f_{2} N-C v-B+q_{m} k_{f} \cos \alpha=0 \\
-\frac{\mathrm{d}^{2} M_{b}}{\mathrm{~d} s^{2}}+T_{t} k_{b}+N_{n}+f_{1} N_{b}+q_{m} k_{f} \frac{k_{\alpha}}{k_{b}} \sin \alpha=0 \\
-k_{b} \frac{\mathrm{d} M_{t}}{\mathrm{~d} s}+N_{b}-f_{1} N_{n}-q_{m} k_{f} \frac{k_{\varphi}}{k_{b}} \sin ^{2} \alpha=0
\end{array}\right.
$$

3.3. Boundary Conditions. There are two working states of the CHSDS: meshing and separation. Different working states correspond to different boundary conditions.

3.3.1. Boundary Conditions of CHSDS Meshing State. When the CHSDS is in the meshing state, like conventional rotary drilling, the drill string rotates as a whole, and the wellhead torque and the bit reverse torque are known. The wellhead torque is the external torque exerted by the rotary table or the top drive, and the bit torque is the reverse torque produced by the PDM. Therefore, the boundary conditions are as follows [33]: 


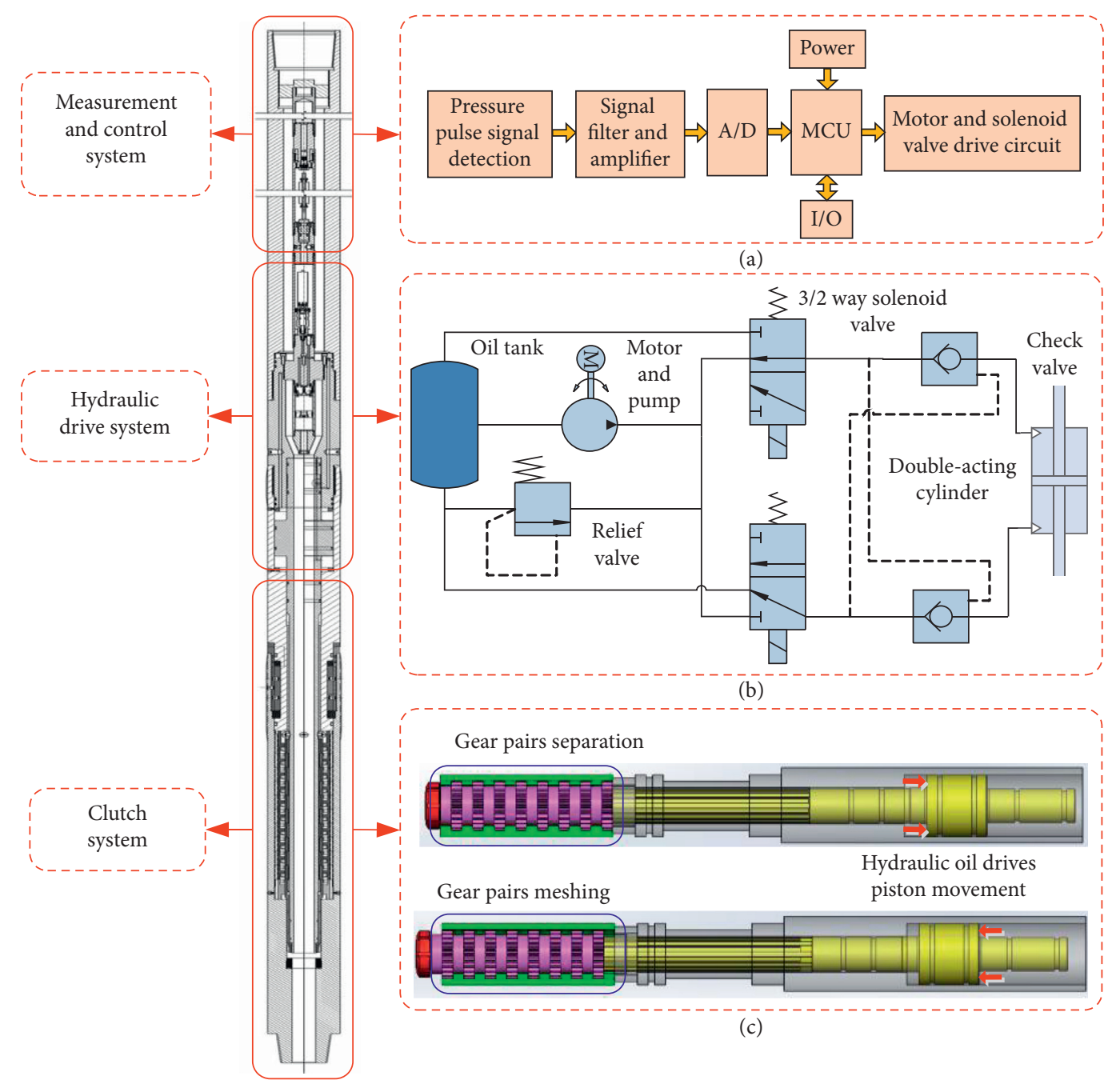

Figure 2: Structure of CHSDS.

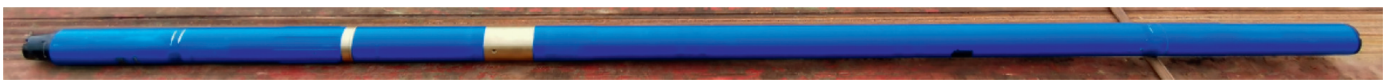

FIgURe 3: Principle prototype of CHSDS.

$$
\left\{\begin{array}{l}
M_{t}\left(s=s_{N}\right)=\mathrm{TOB} \\
T\left(s=s_{N}\right)=-\mathrm{WOB}
\end{array}\right.
$$

where $M_{t}\left(S=S_{N}\right)$ is the torque on the element, $N \cdot m ; S_{N}$ is the drill string length below the node, $m$; $T\left(S=S_{N}\right)$ is the pull at the top of the drill string below the node, $N$; TOB is the torque on the bit, $N \cdot m$; and WOB is the weight on the bit, $N$.

3.3.2. Boundary Conditions of CHSDS Separation State. When the CHSDS is separated, in its working state, the upper drill string rotates and the lower drill string slides. The boundary conditions are shown in Figure 5. Similar to the above scenario, the wellhead torque is the external torque, and the bit torque is the reverse torque generated by the PDM. Therefore, the upper boundary conditions of the drill string below the CHSDS are as follows [33]:

$$
\left\{\begin{array}{l}
M_{t}\left(s=s_{N}\right)=\mathrm{TOB} \\
T\left(s=s_{N}\right)=-\mathrm{WOB} \\
M_{t}\left(s=s_{T}\right)=M_{\mathrm{TL}} \\
T\left(s=s_{\mathrm{TU}}\right)=T\left(s=s_{\mathrm{TL}}\right),
\end{array}\right.
$$

where $M_{t}$ is the friction torque of the CHSDS bearing rotation, $N \cdot m ; T\left(S=S_{\mathrm{TU}}\right)$ is the pull force at the bottom of the drill string above the CHSDS, $N ; T\left(S=S_{\mathrm{TL}}\right)$ is the pull force at the bottom of the drill string below the CHSDS, $N ; S_{T}$ is the installation position of the CHSDS, 

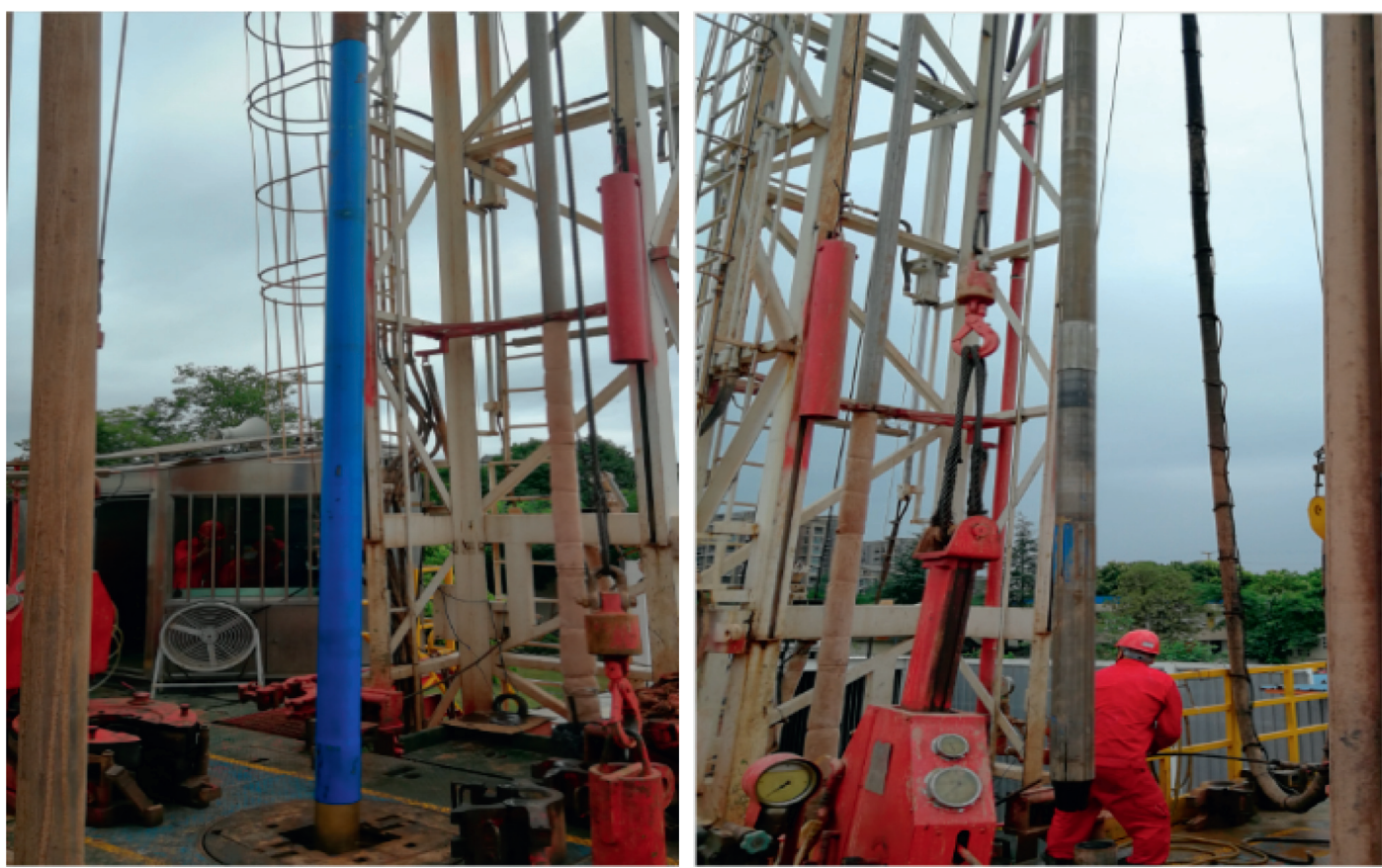

Figure 4: Tool tripping in and tripping out.

Table 1: Drag-reduction test results.

\begin{tabular}{lccccc}
\hline State & Pump strokes (strokes/min) & Rotary speed (rpm) & Tripping out load $(\mathrm{kN})$ & Tripping in load $(\mathrm{kN})$ & Static load $(\mathrm{kN})$ \\
\hline Meshing & 40 & - & 328 & 294.6 & - \\
Meshing & 40 & 30 & - & - & 310.84 \\
Separation & 40 & 30 & - & - & $300-302$ \\
\hline
\end{tabular}

$m$; and $M_{\mathrm{TL}}$ is the torque at the bottom of the drill string below the CHSDS, $N \cdot m$.

The lower boundary conditions of the drill string above the CHSDS are

$$
\left\{\begin{array}{l}
M_{t}\left(s=s_{T}\right)=M_{\mathrm{TU}}, \\
T\left(s=s_{\mathrm{TU}}\right)=T\left(s=s_{\mathrm{TL}}\right),
\end{array}\right.
$$

where $M_{\mathrm{TU}}$ is the torque at the bottom of the drill string above the CHSDS, $N \cdot m$.

3.3.3. Bit Boundary Conditions. In the process of drilling, the formation forces on the bit mainly include the reaction of the $\mathrm{WOB}$, reaction of the bit lateral force, and the friction torque. Therefore, the boundary conditions of the interaction between the bit and the formation can be expressed as follows [34, 35]:

$$
\left\{\begin{array}{l}
F_{\mathrm{wob}}(t)=W_{o}+k_{f} x_{o} \sin \left(2 \pi n_{b} f_{\mathrm{bit}} t\right) \\
T_{\mathrm{bit}}(\varphi, \dot{\varphi})=\frac{1}{3} D_{w} \mu_{k}\left(W_{o}+k_{f} x_{o} \sin n_{b} \varphi_{\mathrm{bit}}\right)
\end{array}\right.
$$

where $W_{o}$ is the average WOB, $k N$; and $n_{b}$ is the incentive factor, dimensionless, related to the type of the bit. In addition, $x_{o}$ is the cutting depth of one turn of the drill bit, $m$; $k_{f}$ is the formation stiffness, $N / m$; $f_{\text {bit }}$ is the fluctuation frequency of the WOB, $\mathrm{Hz}$; and $\mu_{k}$ is the dynamic friction coefficient, dimensionless.

\section{Results and Discussion}

\subsection{Basic Parameters of Case Well}

4.1.1. Well Trajectory and Casing Program. The well depth of the designed three-dimensional (3D) horizontal well is $5016 \mathrm{~m}$, and the casing program profile and the well trajectory are presented in Figures 6 and 7.

According to the $3 \mathrm{D}$ well trajectory, the actual drilling depth of the well is $5000 \mathrm{~m}$, and the deviation angle first increases and then decreases in the shallow vertical section. Simultaneously, the deviation of the horizontal section of the well initially decreases, then increases, and finally decreases. The length of the horizontal section is approximately $1500 \mathrm{~m}$. The wellbore trajectory of this well is complex, and the friction is extremely large.

4.1.2. Bottom Hole Assembly. The BHA is divided into two groups: one group contains the CHSDS and the other group does not include the CHSDS. Specifically,

BHA 1: bit + PDM + bent sub + nonmagnetic drill collar + drill collar + CHSDS + drill pipe 


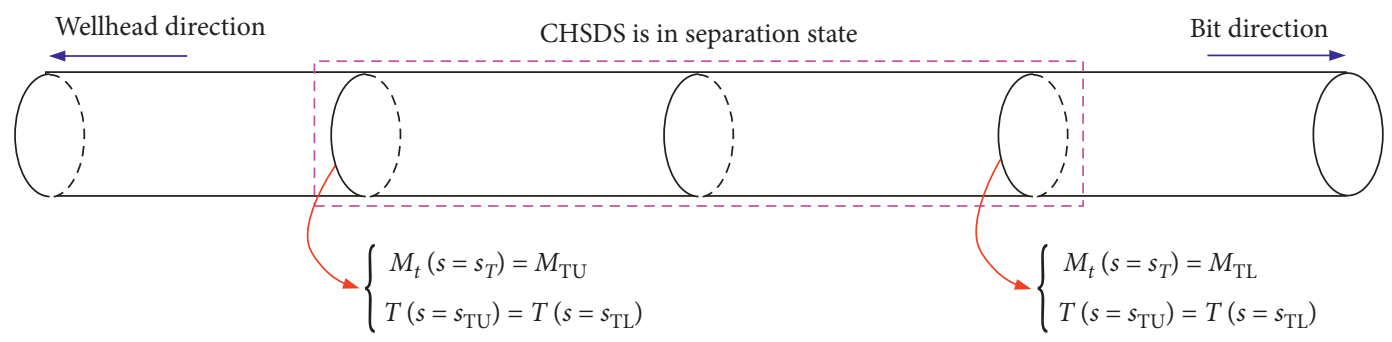

FIGURE 5: CHSDS separation state boundary conditions.

BHA 2: bit + PDM + bent sub + nonmagnetic drill collar + drill collar + drill pipe

4.1.3. Drilling Parameters. The drilling parameters are as follows: WOB of $80 \mathrm{kN}$, displacement of $26 \mathrm{~L} / \mathrm{s}$, drilling fluid density of $2200 \mathrm{~kg} / \mathrm{m}^{3}$, drilling fluid viscosity of $24 \mathrm{mPa} \cdot \mathrm{s}$, and drilling fluid dynamic shear force of $5.5 \mathrm{~Pa}$.

\subsection{Performance Analysis of CHSDS}

\subsubsection{Analysis of CHSDS Drag-Reduction Effect}

(i) Drag and Torque Distribution. The drag distributions of BHA 1, BHA 2, and combined drilling conditions are calculated, which are presented in Figure 8. The load of the hook with the CHSDS is larger than that without the CHSDS, which shows that the CHSDS can effectively reduce the friction of the drill string. Figure 9 shows the variation curves of the drag differences of BHA 1 and BHA 2 with the well depth. In the vertical section, the drag difference basically presents a horizontal line. Thus, there is almost no drag-reduction effect in the vertical section. In the deviated section, the drag difference approximately presents a highslope straight line, indicating that the drag-reduction effect is significant. In the horizontal section, the drag difference is almost linear with a slope less than the slope for the deviated section, indicating that the drag-reduction effect in the horizontal section is notable. However, it is slightly worse than that in the inclined section. In the combined drilling, the drag distribution of the drill string is very close to that of BHA 1. The main difference is that there is no rotating drill string under the CHSDS.

In directional drilling, the rotary torque of BHA 1 is significantly higher than that of BHA 2. The difference in the torques is due to the friction torque generated by the rotation of the drill string above the CHSDS, as shown in Figure 10; installation of the CHSDS has no effect on the torque distribution of the lower drill collar. Therefore, regardless of BHA 1 or BHA 2, the lower drill string uses friction to offset the bit reverse torque. Therefore, the torque distribution of the lower drill string is consistent. The difference is that the friction torque produced by the CHSDS bearing has a weak influence on the torque distribution of the lower drill string near the CHSDS. In the combined drilling, the wellhead torque is greater than that of BHA 1 , whereas the torque distribution law is basically the same. The difference is that the drill string under BHA 1 does not rotate; therefore, the friction torque is smaller than that in the combined drilling.

(ii) Friction Distributions of BHA 1 and $B H A$ 2. The friction distributions of BHA 1 and BHA 2 are shown in Figure 11. The friction force of BHA 1 is slightly larger than that of BHA 2 in the vertical section; this is because the contact force between the drill string and the borehole wall is larger in the rotary drilling than that in the sliding drilling. According to Figure 11, the friction forces produced by BHA 1 and BHA 2 in the deviated section are $253.1 \mathrm{kN}$ and $494.65 \mathrm{kN}$, respectively, and those by BHA 1 are reduced by $48.83 \%$ compared to those by BHA 2 . Because the curvature of the deviated hole increases significantly, the contact force between the drill string and the borehole wall increases significantly. Moreover, based on the principle of frictionreducing resistance of the rotary drill string, the axial friction force of the rotary drilling is smaller than that of the sliding drilling. Similarly, the friction forces produced by BHA 1 and BHA 2 in the horizontal section are $412.95 \mathrm{kN}$ and $572.7 \mathrm{kN}$, respectively, and BHA 1 produces $27.89 \%$ smaller force than BHA 2. The contact force between the drill string and the borehole wall increases significantly because of the bending and stiffness of the drill string in the deviated section. In comparison, the contact force in the horizontal section is mainly generated by gravity. Therefore, the dragreduction effect of the CHSDS in the inclined section is better than that in the horizontal section.

\subsubsection{Analysis of Influence Factors of CHSDS Drag-Reduction Effect}

(i) Influence of CHSDS Installation Position on Friction Force. In the process of drilling with the PDM, the reverse torque generated by the bit is offset by the friction torque between the drill string and the borehole wall below the CHSDS, as shown in Figure 12. Under the same reverse torque condition of the bit, the effects of different CHSDS installation positions on the drag-reduction effect are depicted. It can be seen from the figure that when the CHSDS installation position is close to the bit, the dragreduction effect is large. If the CHSDS is installed extremely far from the drill bit, the axial friction of the drill string in the horizontal section is large, whereas the drag-reduction effect is low. If the CHSDS is installed extremely close to the drill bit, the reverse torque of the drill bit cannot be offset, and the tool surface will be unstable. Therefore, it is necessary to 


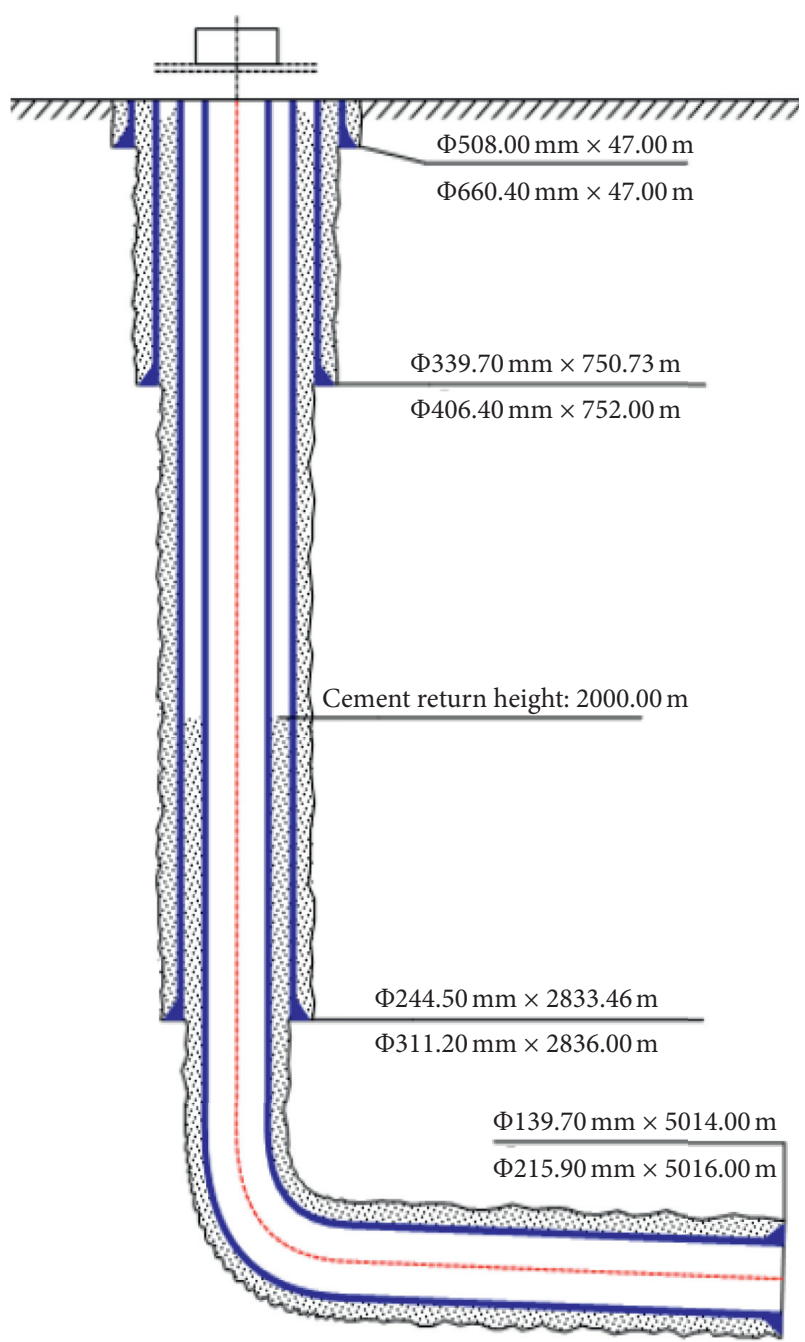

FIGURE 6: Casing program of horizontal well.

ensure that the friction torque of the drill string can offset the reverse torque of the bit, and the closeness between the CHSDS and the bit is associated with a good drag-reduction effect.

(ii) Influence of Rotational Speed on Friction. According to the principle of frictional decomposition, the axial and tangential frictional forces are related to the axial and circumferential speeds. Figure 13 displays the friction curve obtained by changing the rotary speed under the conditions of constant rate of penetration (ROP), WOB, and bit torque. It can be seen from the figure that the friction decreases with the increase in the rotating speed in the inclined and horizontal sections. According to the decomposition principle of the friction force of the drill string compound motion, an increase in the circumferential speed leads to a decrease in the axial friction coefficient, and, therefore, the axial friction force decreases. However, the influence of the rotating speed on the axial friction in the vertical section is not clear. As can be noted from the figure, with the increase in the rotating speed, the effect of drag reduction in the inclined section is the best, followed by that in the horizontal section. However, the effect of drag reduction in the vertical section is not notable.

(iii) Effect of WOB on Friction. The change in the WOB will lead to a change in the contact force of the drill string in the curved well section, causing a change in the axial friction force of the drill string. As displayed in Figure 14, in the vertical section, the change in the WOB does not lead to a change in the friction force because the increase in the axial force in the vertical section does not modify the contact force. In the deviated section, the axial friction increases with the increase in the WOB because the contact force between the drill string and the wellbore increases with the increase in the WOB. In the horizontal section, with the increase in the WOB, the axial friction force of the drill string does not increase significantly; however, the fluctuation amplitude increases significantly. As the WOB of the horizontal section increases, the contact force of the smooth horizontal section does not increase, whereas the contact force of the curved section increases significantly.

(iv) Effect of Drilling Fluid Density on Friction. The density of the drilling fluid determines the floating weight of the drill string, and it changes the contact force of the drill string and the wellbore. Therefore, it has an impact on the friction force of the drill string. From Figure 15, we can see that the distribution curve of the drill string friction force with the variation in the drilling fluid density. With the increase in the drilling fluid density, the axial friction of the drill string decreases gradually because a high-density drilling fluid is associated with a small floating weight of the drill string. Furthermore, a small contact force between the drill string and the borehole wall corresponds to a small friction force.

4.3. Discussion of Simulation Results. Based on Figure 11, compared to the conventional sliding steering drilling, the drag-reduction effect of the CHSDS can reach $48.83 \%$ in the deviated section and $27.89 \%$ in the horizontal section. This is based on a given case of well-calculated parameters; it is not universal. Moreover, because of the effect of the drag reduction and well trajectory, the installation position, rotary speed, WOB, and drilling fluid present close relations. Although the results of the calculations with different drilling parameters are not the same, the simulation results can be qualitatively explained in that, in the drilling process of a particular horizontal well, the deviated section of the CHSDS has a better drag-reduction effect than the horizontal section.

Because a 3D horizontal well drill string dynamic model calculation is complex and time-consuming, it is not conducive to field promotion. Considering that the axial velocity of the drill string during horizontal well drilling is very low, the calculation of the drag torque during the drilling of the drill string mainly focuses on the drill string static balance, instead of the instantaneous dynamic response as a drill string vibration $[5,26,34]$. To simplify the calculation and ignore the effect of the dynamic load, a static model is used, which is different from the actual scenario. 


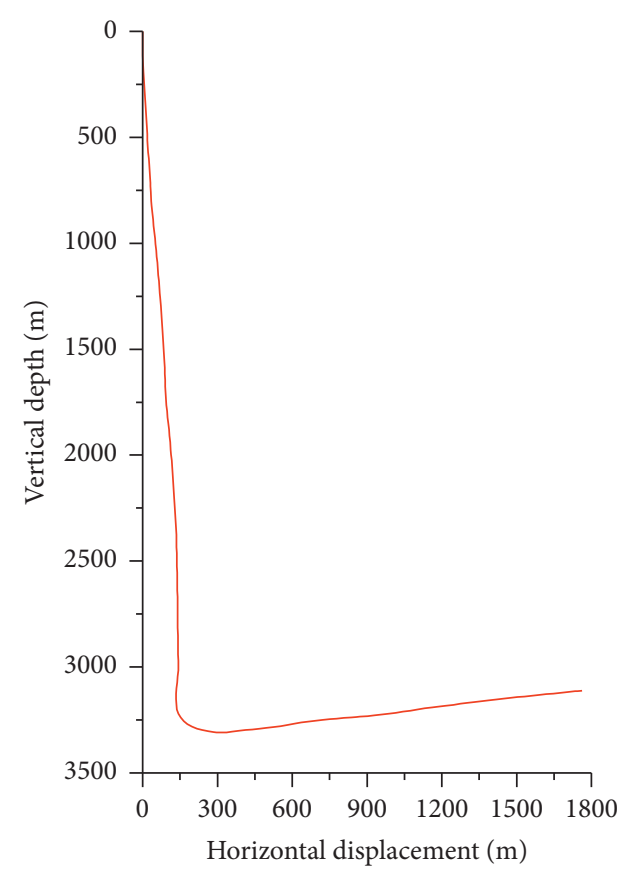

(a)

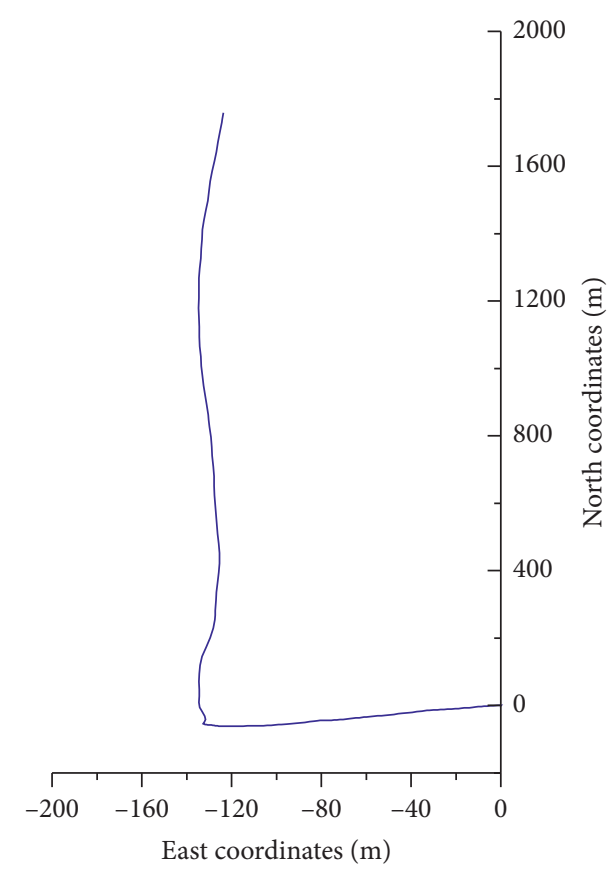

(b)

Figure 7: Horizontal well trajectory. (a) Vertical projection view. (b) Horizontal projection view.

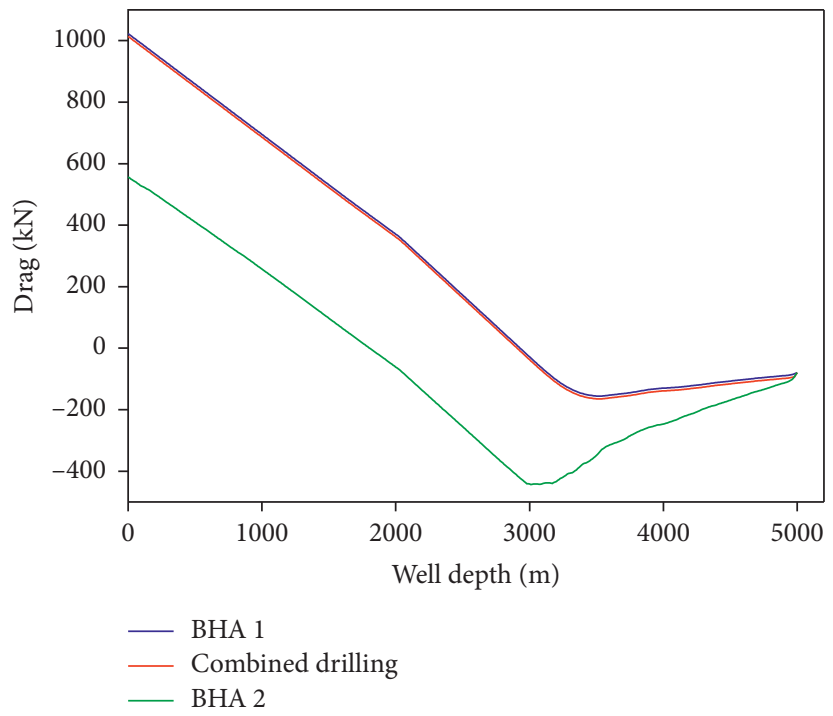

FIGURE 8: Drag force variation with well depth.

In the process of horizontal well drilling, the recommended drilling tool assembly is bit + PDM + bent sub + nonmagnetic drill collar + drill collar + CHSDS + drill pipe. The downhole function test is conducted for the system; however, it does not test its actual drag-reduction effect during the drilling in horizontal and deviated sections. The simulated drag-reduction effect needs to be further confirmed by field tests. The next steps will be to conduct the downhole drag reduction performance test of the system and subsequently perform a comparison with the model calculation results. This will be followed by the analysis and modification of the model to improve the prediction accuracy as well as provision of a theoretical basis for the subsequent application of the system. 


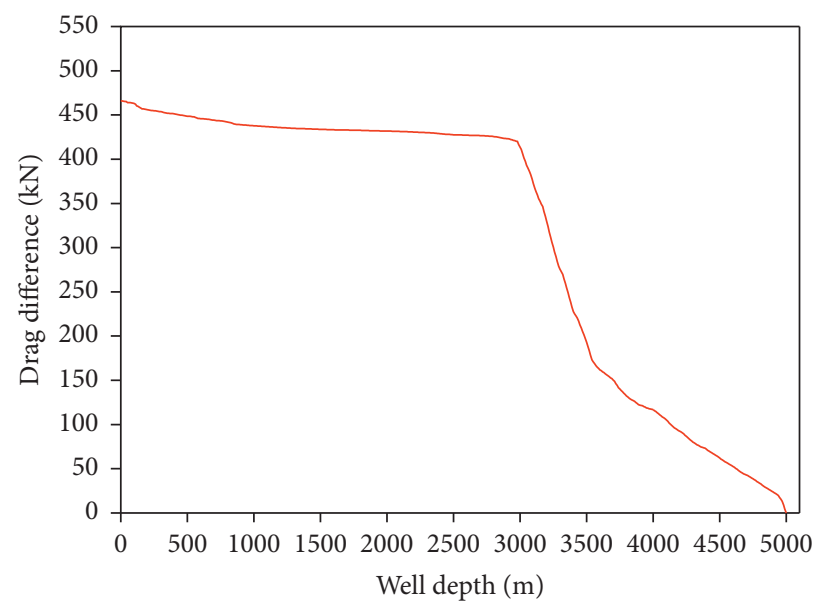

Figure 9: Drag difference between BHA 1 and BHA 2.

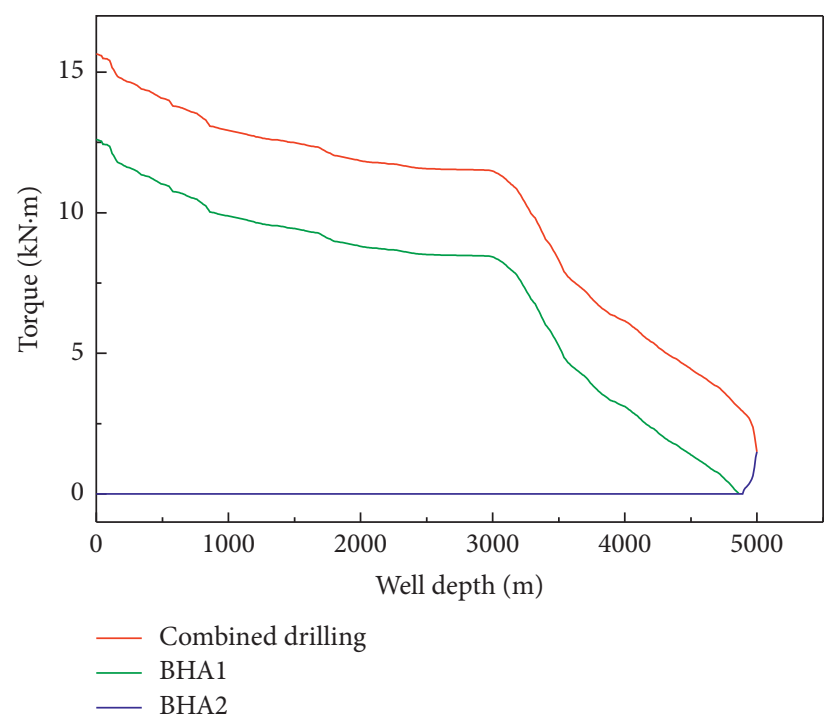

FIgURE 10: Relationship between torque and well depth.

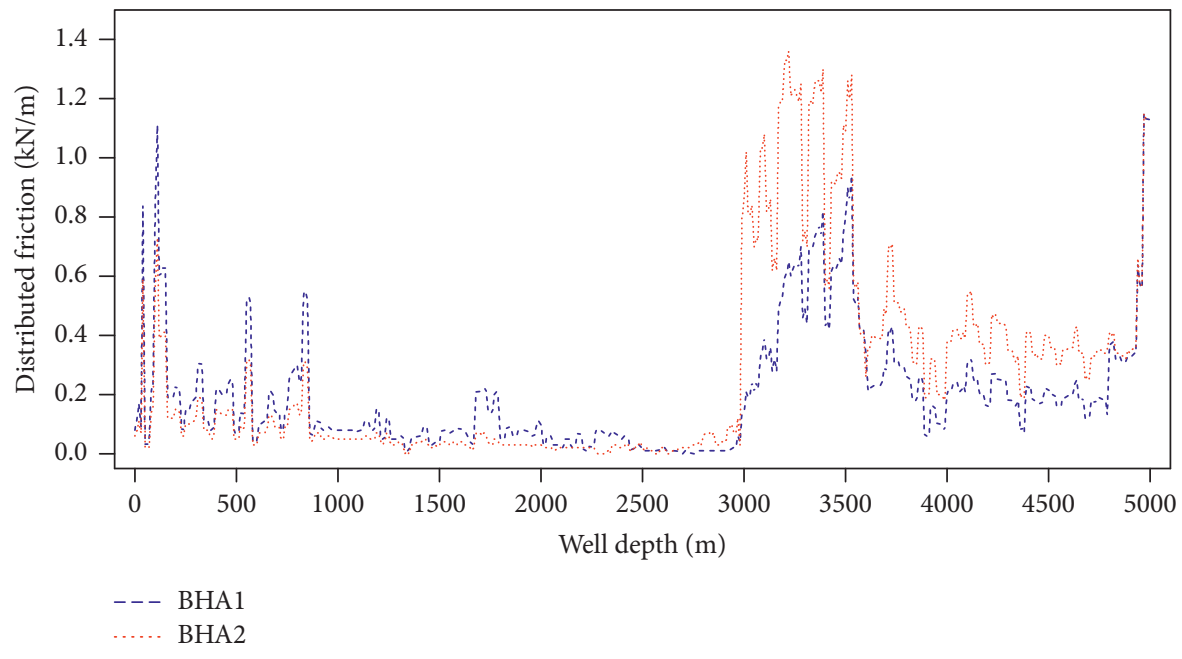

FIGURE 11: Distribution of friction force with and without CHSDS. 


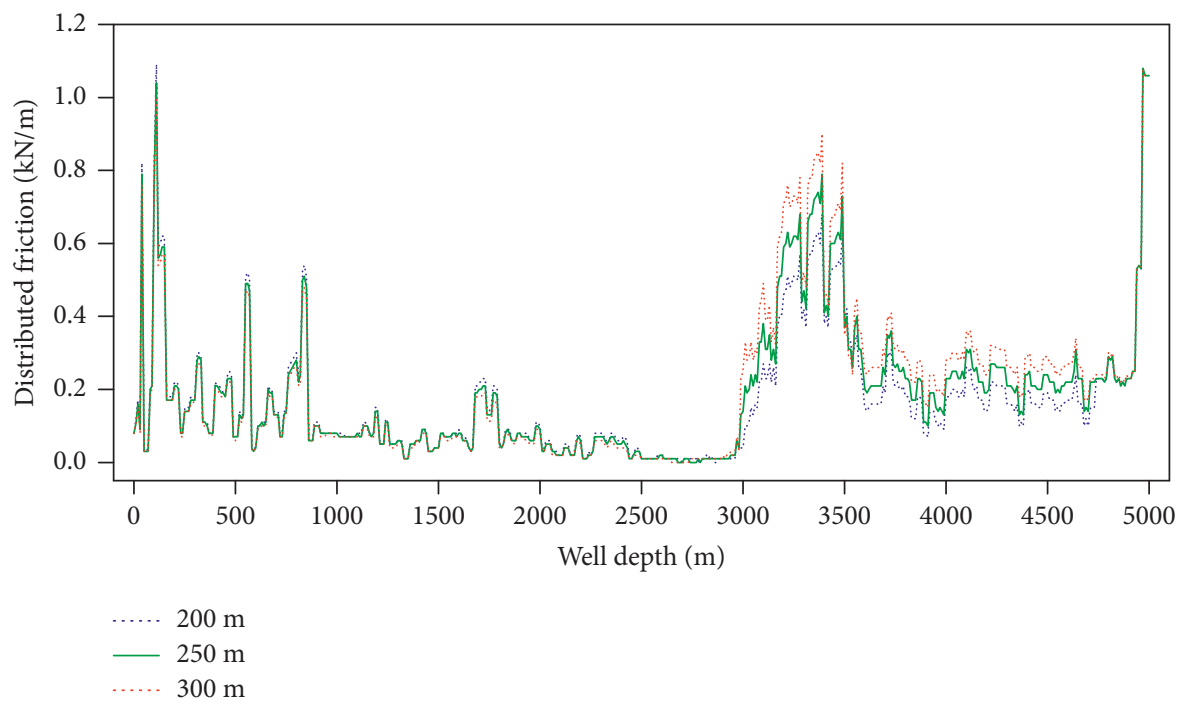

FIGURE 12: Influence of tool installation position on friction.

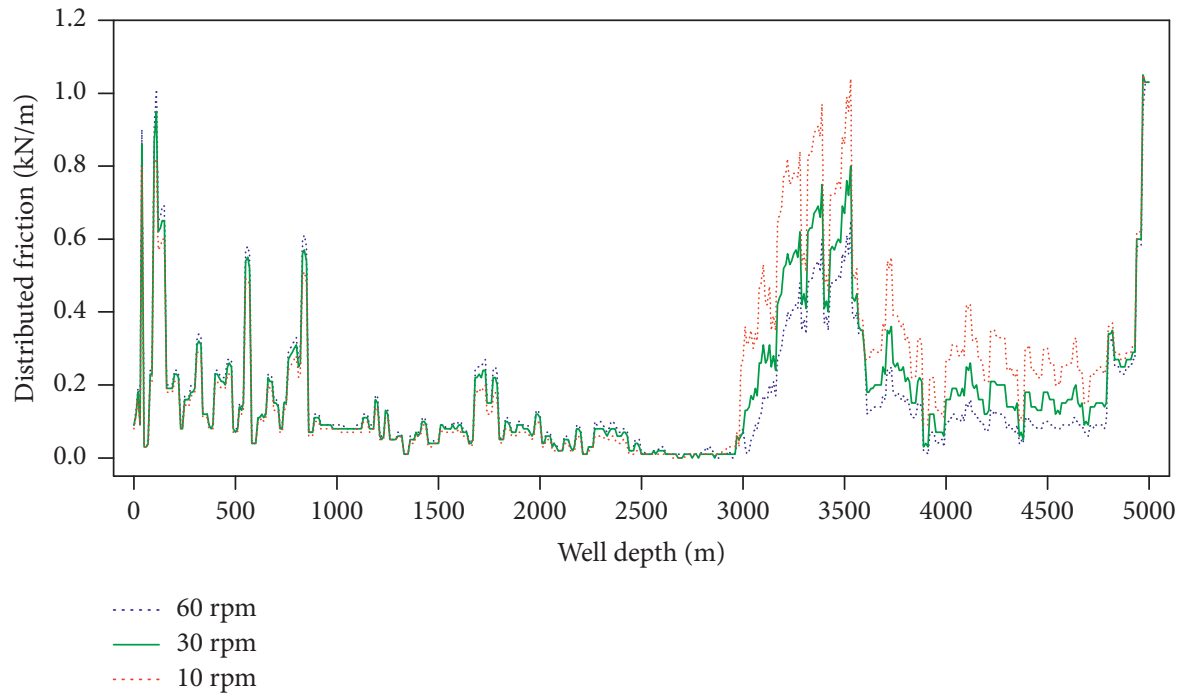

Figure 13: Effect of rotational speed on friction.

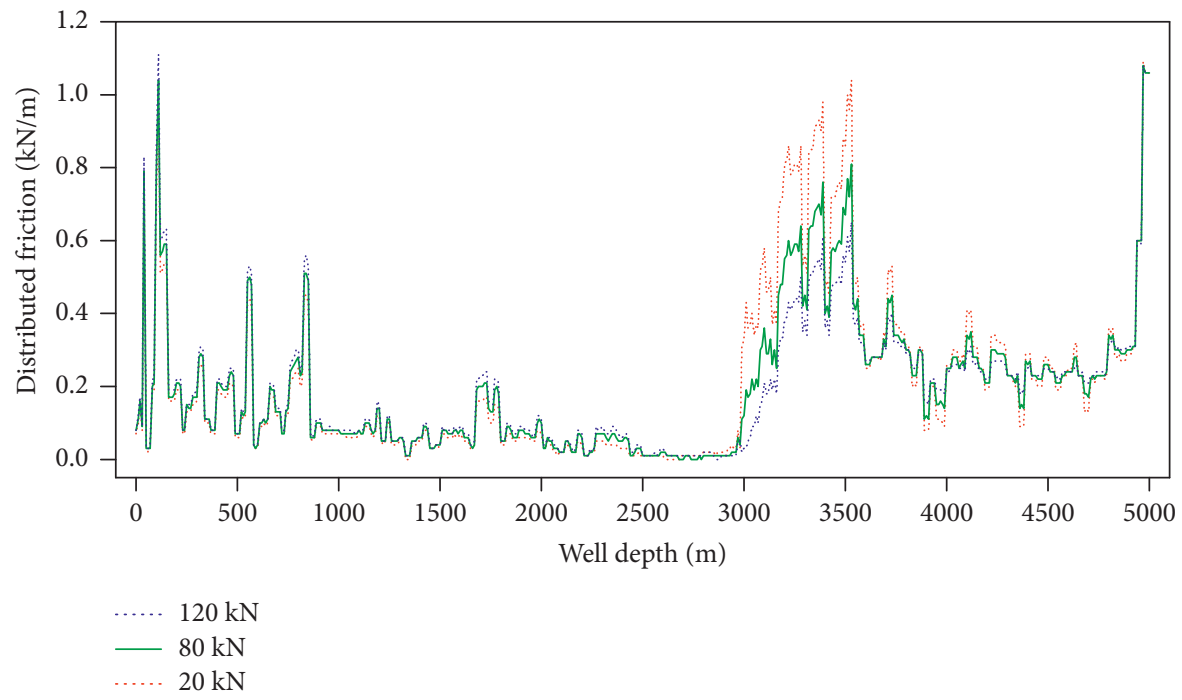

Figure 14: Effect of WOB on friction. 


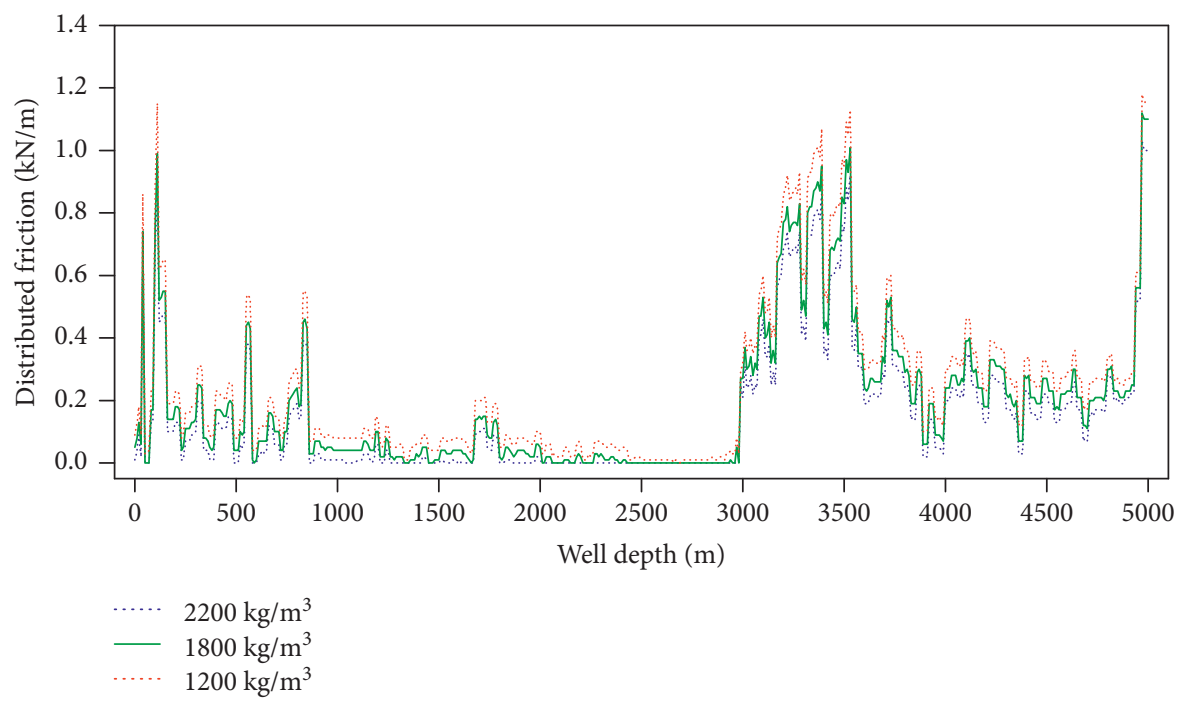

Figure 15: Effect of drilling fluid density on friction.

\section{Conclusion}

To cope with the extreme friction, torque, and backing pressure during sliding drilling of extended-reach wells and horizontal wells, a novel controllable hybrid steering drilling system has been developed, and field function tests and numerical simulations have been carried out. According to the test and analysis results, the following conclusions are drawn:

(1) Based on the principle of reducing the friction of a rotary drill string, a novel controllable hybrid steering drilling system is developed, and the design function was verified by field test.

(2) According to the working mode of the CHSDS, two types of boundary conditions in the meshing and separation states are determined. Combined with stiffstring model, the drag-reduction effect and the influence of the drilling parameters on the CHSDS are analyzed.

(3) The simulation results show that the drag-reduction effect in the inclined section is the best, reaching $48.83 \%$, followed by that in the horizontal section, reaching $27.89 \%$, whereas the vertical section presents little drag-reduction effect.

(4) Under the same conditions, as the rotation speed and drilling fluid density increase, the axial friction of the drill string decreases. However, as WOB and distance between the CHSDS and the drill bit increase, the axial friction of the drill string increases.

\section{Data Availability}

The data used to support the findings of this study are included within the article.

\section{Conflicts of Interest}

The authors declare that they have no conflicts of interest.

\section{Acknowledgments}

This work was supported by the National Science and Technology Major Project of China (Grant no. 2016ZX05022-01) and the China Postdoctoral Science Foundation Funded Project (Grant no. 2020M673576XB). The authors express their deep gratitude for the invaluable support of the institution.

\section{References}

[1] M. Kenomore, M. Hassan, H. Dhakal, and A. Shah, "Economic appraisal of shale gas reservoirs," in Proceedings of the SPE Europec Featured at 80th EAGE Conference and Exhibition, Copenhagen, Denmark, June 2018.

[2] Z. F. Xiang, Z. X. Quan, L. Z. Bin et al., "Practice of drilling optimization system in the development of unconventional oil and gas resources in China," China Petroleum Exploration, vol. 25, no. 2, pp. 96-109, 2020.

[3] S. H. Fang, B. Jing, H. Bing et al., "Unconventional shale gas drilling comparison in Sichuan basin, China different approaches aim for same target," in Proceedings of the Offshore Technology Conference-Asia, Kuala Lumpur, Malaysia, March 2014.

[4] Z. J. Cheng, Z. H. Bo, Z. Y. Bin, and N. X. Ming, "Optimal and fast drilling technology for shale gas horizontal well and its application," in Proceedings of the SPE/IATMI Asia Pacific Oil and Gas Conference and Exhibition, Jakarta, Indonesia, October 2017.

[5] W. X. Ying, N. H. Jian, W. R. He, L. T. Ke, and X. J. Guo, "Modeling and analyzing the movement of drill string while being rocked on the ground," Journal of Natural Gas Science and Engineering, vol. 39, pp. 28-43, 2017.

[6] L. Yang, C. Ping, W. X. Ming, and M. T. Shou, "Modeling friction-reducing performance of an axial oscillation tool using dynamic friction Model," Journal of Natural Gas Science and Engineering, vol. 33, pp. 397-404, 2016.

[7] J. Garcia, S. Banks, M. John, P. Vertex, B. Robert, and R. Resources, "Field-verified modeling compares weight transfer methods in horizontal wells," in Proceedings of the 
SPE/IADC Drilling Conference and Exhibition, The Hague, The Netherlands, March 2019.

[8] I. Rostahno, M. Yi, P. Ashok, E. V. Oort, B. Potash, and C. Mullin, "A methodology for selecting optimal pipe rocking regimes during slide drilling," in Proceedings of the SPE/ AAPG/SEG Unconventional Resources Technology Conference, Denver, CO, USA, July 2019.

[9] N. Alnahash, M. Alghofaili, S. Aramco, A. A. Khalifah, and M. Ali, "Drilling optimization approach in performance enhancement and cost reduction using a friction-reduction tool in challenging applications," in Proceedings of the SPE International Petroleum Technology Conference, Dhahran, Saudi Arabia, January 2020.

[10] L. Yang, C. Ping, M. T. Shou, and W. X. Ming, "An evaluation method for friction-reducing performance of hydraulic oscillator," Journal of Petroleum Science and Engineering, vol. 157, pp. 107-116, 2017.

[11] E. Maidla and M. Haci, "Understanding torque: the key to slide-drilling directional wells," in Proceedings of the IADC/ SPE Drilling Conference, Dallas, TX, USA, March 2004.

[12] L. Yang, M. T. shou, C. Ping, and Y. Chuan, "Method and apparatus for monitoring of downhole dynamic drag and torque of drill-string in horizontal wells," Journal of Petroleum Science and Engineering, vol. 164, pp. 320-332, 2018.

[13] S. Y. Nao, D. X. Rong, and W. J. Jin, "Antifriction tool and its application," Oil Drilling \& Production Technology, vol. 27, pp. 78-80, 2005.

[14] J. E. McCormick, T. Long, and M. Frilot, "Inaccessible drilling targets and completions operation made possible by the alleviation of excessive torque and drag," in Proceedings of the SPE Middle East Drilling Technology Conference and Exhibition, Manama, Bahrain, October 2009.

[15] J. E. McCormick, G. Osorio, J. Andachi, and M. Barth, "Adjustable gauge stabilizer and torque and drag reduction tools reduce overall drilling times by at least 20\%: a case study," in Proceedings of the SPE Middle East Oil and Gas Conference, Manama, Bahrain, September 2011.

[16] M. Warner and R. A. Hall, "Benefits of using downhole vibratory casing tools in the niobrara/codell formations," in Proceedings of the IADC/SPE Drilling Conference and Exhibition, Fort Worth, TX, USA, March 2016.

[17] T. J. Lin, Y. Zhi, L. You et al., "Vibration analysis of new drill string system with hydro- oscillator in horizontal well," Journal of Mechanical Science \& Technology, vol. 30, pp. 2443-2451, 2016.

[18] T. Mcintosh, K. J. Gervais, J. G. Gervais, R. Schultz, and J. Whitworth, "A vibratory tool study on extended reach horizontals during coiled tubing drillout in the eagle ford shale," in Proceedings of the SPE/ICoTA Coiled Tubing and Well Intervention Conference and Exhibition, Houston, TX, USA, March 2016.

[19] O. Hummes, S. Janwadkar, J. Powers et al., "Evolution of high build-rate RSS changes the approach to unconventional oil and gas drilling," in Proceedings of the SPE Annual Technical Conference and Exhibition, Denver, CO, USA, October 2011.

[20] C. Gillan, S. Boone, G. Kostiuk, C. Schlembach, J. Pinto, and M. Leblanc, "Applying precision drill pipe rotation and oscillation to slide drilling problems," in Proceeedings of the SPE/ IADC Drilling Conference and Exhibition, Amsterdam, The Netherlands, March 2009.

[21] C. Gillan, S. Boone, M. LeBlanc, R. Picard, and T. Fox, "Applying computer based precision drill pipe rotation and oscillation to automate slide drilling steering control," in
Proceedings of the SPE Canadian Unconventional Resources Conference, Calgary, Alberta, November 2011.

[22] W. X. Ying, Development of Torque Clutch Drilling Tool and Evaluation of Drag Reduction Performance, Southwest Petroleum University, Chengdu, China, 2017.

[23] H. L. Xiang, Z. J. Chuan, and L. Wei, "Application evaluation of the PIPE ROCK twist drill string system," Natural Gas Industry, vol. 38, pp. 73-78, 2018.

[24] C. Pehlivantürk, J. D. Angelo, C. D. Zhou, C. D. Mei, and E. V. Oort, "Slide drilling guidance system for directional drilling path optimization," in Proceedings of the SPE/IADC International Drilling Conference and Exhibition, The Hague, The Netherlands, March 2019.

[25] V. S. Tikhonov, A. I. Safronov, K. R. Valiullin, and O. S. Bukashkina, "Development of universal application for drillstring dynamics simulation," in Proceedings of the SPE Russian Oil and Gas Technical Conference and Exhibition, Moscow, Russia, October 2014.

[26] R. F. Mitchell and R. Samuel, "How good is the torque/drag model?" in Proceedings of the SPE/IADC Drilling Conference and Exhibition, Amsterdam, The Netherlands, February 2009.

[27] G. D. Li and H. W. Jun, "A review of down-hole tubular string buckling in well engineering," Petroleum Science, vol. 12, pp. 443-457, 2015.

[28] L. Z. Feng, Z. C. Yue, and S. G. Ming, "Research advances and debates on tubular mechanics in oil and gas wells," Journal Petroleum Science and Engineering, vol. 151, pp. 194-212, 2017.

[29] L. J. Yuan and L. Z. Feng, Prediction and Diagnosis of SuckerRod Pumping Systems in Directional Wells?, SPE 57014, Society of Petroleum Engineers, Dallas, TX, USA, 1999.

[30] L. Z. Feng, L. X. Sheng, Z. D. Qian, and Z. S. Nan, A Steady Tension-Torque Model for Drillstring in Horizontal Wells, SPE 26295, Society of Petroleum Engineers, Dallas, TX, USA, 1993.

[31] H. G. Lu, Study on Drillstring Torsional Vibration in Extended Reached Well, University of Petroleum, Dongying, China, 2002.

[32] H. S. Ho, "An improved modeling program for computing the torque and drag in directional and deep wells," ", in Proceedings of the SPE Annual Technical Conference and Exhibition, Houston, TX, USA, October 1988.

[33] W. X. Ming, P. Chen, H. W. Zhi, and Z. J. Yan, "Development of torque clutch drilling tool and evaluation of drag reduction performance," Advances in Mechanical Engineering, vol. 10, pp. 1-20, 2018.

[34] M. W. Dykstra, Nonlinear Drill String Dynamics, University of Tulsa, Tulsa, OK, USA, 1996.

[35] H. Y. Bao, D. Q. Feng, Z. W. Ping, C. Z. Feng, and W. W. Chang, "Dynamic characteristics analysis of drillstring in the ultra-deep well with spatial curved beam finite element," Journal of Petroleum Science and Engineering, vol. 82, pp. 166-173, 2012. 